\title{
Dynamic interdependencies among the housing market, stock market, policy uncertainty and the macroeconomy in the United Kingdom
}

\author{
Nikolaos Antonakakis ${ }^{\mathrm{a}, \mathrm{b}, *}$, Christos Floros ${ }^{\mathrm{c}, \mathrm{d}}$ \\ ${ }^{a}$ Webster Vienna University, Department of Business \& Management, Praterstrasse 23, 1020, Vienna, \\ Austria. \\ ${ }^{b}$ University of Portsmouth, Department of Economics and Finance, Portsmouth Business School, \\ Portland Street, Portsmouth, PO1 3DE, United Kingdom. \\ ${ }^{c}$ Technological Educational Institute of Crete, Department of Accounting and Finance, 71004 Crete, \\ Greece. \\ ${ }^{d}$ Hellenic Open University, School of Social Sciences, Greece.
}

\begin{abstract}
In this study we examine the dynamic interdependencies among the housing market, stock market, policy uncertainty and the macroeconomy in the United Kingdom, over the period 1997M1-2015M02. The findings of this study suggest the following empirical regularities. First, the transmission of various types of shocks contributes significantly to economic fluctuations in the United Kingdom. Second, spillovers show large variations over time. Third, in the wake of the global financial crisis, spillovers have reached unprecedented levels. Specifically, we find large spillovers of shocks from the housing market, stock market and economic policy uncertainty to inflation, economic growth, and monetary policy stance. These results illustrate the contagion from the housing and financial crisis to the real economy and the policy reaction to stabilise the economy.
\end{abstract}

Keywords: Housing market, Stock market, Economic policy uncertainty, Spillover, Vector autoregression, Impulse response

JEL codes: C32; E40; E50; G10; G20

*Corresponding author: Phone: +43 126990934373, e-mail: nikolaos.antonakakis@webster.ac.at. Email addresses: nikolaos.antonakakis@webster.ac.at; nikolaos.antonakakis@port.ac.uk (Nikolaos Antonakakis), cfloros@staff.teicrete.gr (Christos Floros) 


\section{Introduction}

Following the recent global financial crisis (GFC), financial markets around the globe have undergone a period of unprecedented turmoil. In turn, this has contributed to increased uncertainty in global economic conditions and policy responses, and heightened the uncertainty of investment markets including real estate.

Despite such developments, there exist no study, according to our knowledge, that examines the interdependencies among housing markets, stock markets, policy uncertainty and responses, and the real economy in a unified framework.

The literature suggests the existence of a feedback mechanism between housing and macroeconomic variables. On the one hand, housing markets follow changes in the economic variables (see, e.g. Hwang and Quigley, 2006). On the other hand, house prices also play a powerful role and affect macroeconomic variables (Beltratti and Morana, 2010). According to Nneji et al. (2013), an increase in the interest rate is expected to drive borrowing rates up, thus decreasing the demand for properties and falling their prices. Rising interest rates could also lead to a fall in property prices. Further, inflation growth is expected to have a negative effect on the housing market, while the opposite happens for disposable income. ${ }^{1}$

It is obvious that real estate market behaviour is important for investors and households. The 2008 subprime mortgage crisis that originated in the United States had a negative impact on real estate prices in most countries; therefore, the examination of real estate prices is still of great interest to economists, policy makers and other alike, around the world.

In order to explain the recent financial crisis of 2008, many researchers have focused on the housing market as a possible source of macroeconomic fluctuations. Following the Lehman default in 2008, the global financial crisis has opened new discussions on the monetary, macroeconomic and regulatory policies; these also include the fluctuations of housing markets, i.e. booms and busts in real estate prices.

\footnotetext{
${ }^{1}$ For a more detailed description of the theoretical relationship between housing and the macroeconomy, see Davis and Nieuwerburgh (2015).
} 
Although many theoretical models published before 2008 so as to explain the linkages between house prices and real economic activity (e.g. Bernanke et al., 2005; Iacoviello, 2005, amongst others), some post-2008 empirical studies examine the housing cycles and their impact on the global economy (see for example Cesa-Bianchi, 2013; Agnello and Schuknecht, 2011).

A detailed review of the literature on the link between macroeconomics and housing markets is given by Leung (2004). He reports that the plain response in housing is a large share of the overall macroeconomy. In other words, housing constitutes a significant share of household expenditure and total wealth, thus significant fluctuations in housing prices imply significant fluctuations in wealth Leung (2004).

Many empirical papers examine the macroeconomic determinants of house prices, i.e. the dynamic relationship between key economic variables and the dynamics of real estate prices (such as interest rates, inflation, unemployment and economic growth). For example, Iacoviello and Minetti (2003) find that UK house prices are sensitive to interest rate changes. Further, Himmelberg et al. (2005) confirm that interest rates are the most important explanatory variable. They argue that house prices are more sensitive to longterm interest rates. Moreover, Adams and Füss (2010) report that short term interest rates adversely affect demand for houses because of the effect on mortgage rates and the cost of financing for construction firms (see also Nneji et al., 2013; Bouchouicha and Ftiti, 2012; McQuinn and O'Reilly, 2008). Furthermore, the study by Brunnermeier and Julliard (2008) confirms that inflation influences the price-rent ratio for houses. Ling and Naranjo (1999) find that unexpected inflation, yield spread and Treasury bill rate explain changes in real estate market; similarly with Brooks and Tsolacos (1999) for UK and Englund and Ioannides (1997) for 15 OECD countries. Recently, Nneji et al. (2013) provide a detailed explanation of the impact of macroeconomic (inflation, disposable income growth, short rate and the term structure of interest rates) fluctuations on the U.S. housing market. They find that the sensitivity of the real estate market to economic changes is regimedependent. Specifically, they report that changes of macroeconomic variables significantly affect the dynamics of house prices in the steady-state and boom regimes only.

The interlinkages between monetary variables, house prices and the macroeconomy are 
multi-faced (e.g. see Goodhart and Hofmann, 2008). Specifically, Goodhart and Hofmann (2008) find a significant multidirectional link between house prices and the macroeconomy for 17 industrialized countries over the period 1970-2006. They report that shocks to GDP, the CPI and the interest rate have significant effects on house prices. Calza et al. (2013) report that house prices are more responsive to policy shocks in countries with more developed/flexible mortgage markets. In addition, Agnello and Schuknecht (2011) report that interest rates have a significant influence on the probability of booms and busts in housing markets over the period 1980-2007. Further, Beltratti and Morana (2010) examine the linkages between macroeconomic fluctuations and G-7 international house prices. They report a bidirectional linkage. They find that house price shocks produce large effects on the macroeconomy (the links take place through supply shocks and interest rates). Beltratti and Morana (2010) show that $40 \%$ of the variation in G-7 house prices is caused by macroeconomic shocks. Recently, Cesa-Bianchi (2013) examines the international spillovers of housing demand shocks on real economic activity using a Global VAR. The results confirm the existence of strong international spillovers to advanced economies; however, this is not true for emerging economies.

Furthermore, real estate and stocks are important assets for investors, and both are influenced by economic conditions (see, e.g. Lin and Lin, 2011). Many studies relate the real estate and stock markets, and support the notion that these markets are segmented (see, for example Miles et al., 1990; Liu et al., 1990). More specific, Liu et al. (1990) provide evidence of a relationship between stock returns and real estate assets returns. They conclude that segmentation does exist as the result of indirect barriers such as the cost, amount and quality of information for real estate. Lizieri and Satchell (1997) examine the relationships between real estate and the rest of the economy. They conclude that the UK economy leads the real estate market in the short-term. However, with a longer lag structure, they find that positive real estate returns show negative future returns in the rest of the economy. Further, Quan and Titman (1999) report a non-significant contemporaneous relationship between yearly real estate price changes and stock returns. Tse (2001) shows that the Hong Kong property prices and stock market (Hang Seng index) are cointegrated. Okunev et al. (2002) find strong unidirectional causality from 
the Australian stock market to the Australian real estate market. They report that stock market movements lead real estate movements. Apergis and Lambrinidis (2011) show that stock and real estate markets from UK and US are integrated over the period 19852006, implying the absence of gains for portfolio holders that include both assets in those portfolios. Recently, Chan et al. (2011) report contagion between stock, oil and real estate markets.

Recent literature has recognized the need to understand dynamic interdependencies among housing market and key economic variables. In other words, it is apparent from the above discussion that it is not clear whether, and in what magnitude, the current economic uncertainty interacts with housing prices.

Against this backdrop, this is the first study that provides a detailed examination on the dynamic interdependencies among housing market, stock market, policy uncertainty and key macroeconomic variables for UK over the period January 1997 to February 2015. Our goal is to help policy makers to select tools for reducing economic uncertainty and make the UK housing market ${ }^{2}$ more healthy (see also Cesa-Bianchi, 2013). The reasons behind the choice of the UK market in this study are straightforward. First, the UK housing market has been one with the highest price decline since the global financial crisis (Schindler, 2014). According to Tse et al. (2014), the recent financial crisis produced major shocks in the UK housing market. Higgins (2007) argues that real estate forms an important asset class for mutual funds both locally and globally accounting for around $10 \%$ of UK portfolio investment (see also Heaney and Sriananthakumar, 2012). Further, the UK housing market plays an important role in UK economic activity due to a high owner-occupation rate. However, the dynamics of UK housing market are complex (Tse et al., 2014). Tse et al. (2014) report that the UK market faced a problem related to the supply of finance, known as the credit crunch, and therefore real prices across the UK

\footnotetext{
${ }^{2}$ We consider monthly data of UK house prices (average prices); UK house prices reflect the interaction of the demand and supply sides of the market. Statistics show that average house prices rose dramatically in UK regions in the early 2000s, peaking in $2007 £ 251857$ from £118061 in 2000 (detached house), $£ 178051$ from $£ 74453$ (semi-detached house), £141191 from $£ 61641$ (flat), and £153460 from £61357 (terraced house). The average prices for the period 2008-2014 are £232979 (detached house), £162843 (semi-detached house), £130000 (flat), and £138499 (terraced house).
} 
began to fall from the middle of 2007.

The methodology considered in this paper enables us to estimate the spillover indices as given by Diebold and Yilmaz (2012), and trace their magnitude and evolution in a time-varying fashion. To our knowledge, this is the first study that applies the spillover index approach introduced by Diebold and Yilmaz (2012) in the context of the dynamic interdependencies among the aforementioned variables in the UK. Further, this is the first research that examines the interdependencies of housing markets and economic policy uncertainty, as well as stock markets, output growth, inflation and monetary policy stance, which are chosen to provide a fairly comprehensive view of the UK economy, while keeping the model tractable.

To be more specific, our work contributes to the existing empirical literature in several ways. First, we analyse in greater details the UK housing market using recent data. Second, we extend the existing research focused on the linkages between housing prices and other variables (macroeconomic, stock market and policy related), by providing both static and, especially, dynamic spillovers using rolling window estimations. We look at the contributions of shocks to variables affecting housing policy. In addition, we discuss the spillover plots which help us to provide important conclusions and recommend policy implications for the UK. The general motivation for this kind of relationship provided from our study is the fact that economic analysts will be able to forecast future shocks to UK housing market.

We use data provided by the Nationwide Building Society from the UK, which have been widely used by previous studies. Nationwide Building Society ${ }^{3}$ represents one of the largest mortgage providers as they provide the largest house price data compared to other UK property data providers, such as the Land Registry and Halifax.

The main findings can be summarized as follows: both the total and directional spillovers across our set of variables are relatively high during our sample period. Interestingly, we also find that we also find that the transmission of various types of shocks contributes significantly to economic fluctuations in the United Kingdom. Moreover,

\footnotetext{
${ }^{3}$ The Nationwide Building Society indices are mix-adjusted to track a representative house price over time better than the simple average price (see www.nationwide.co.uk).
} 
spillovers show large variations over time, while in the wake of the global financial crisis, spillovers have reached unprecedented levels. Spillover plots show the contagion from the housing and financial crisis to the real economy and the strong policy reaction to stabilise the UK economy. We also argue that policymakers should adopt a wider view of the UK economy and complement targeted measures with broader macroeconomic tightening (see, e.g. Crowe et al., 2013).

The remainder of the article is organized as follows. Section 2 discusses the application of the spillover index approach and describes the data used. Section 3 presents the empirical findings. Section 4 summarizes the main results and concludes.

\section{Data and Methodology}

\subsection{Data}

We collect monthly series of the economic policy uncertainty index (EPU), house price index (HP), consumer price index (CPI), industrial production index (IP), FTSE100 stock market price index (FTSE100), and the interest rate (IR), over the period January 1997 to February 2015. The EPU comes from Baker et al. (2012) and measures policy-related economic uncertainty in the United Kingdom. ${ }^{4}$ The house price index is obtained from Nationwide database and the remaining series from Datastream, and converted to real returns (apart from the interest rate) by taking the 12-month difference of the natural logarithm of the real variable (i.e. deflated by CPI), e.g. for the house price index $\left(r H P_{t}\right)$ : $100 \times\left(\log \left(r H P_{t}\right)-\log \left(r H P_{t-12}\right)\right)$. In the case of the interest rate, we take the first differences so as to render the series stationary. The motivation for including these series is to look at which shocks contributed most to macroeconomic volatility over time. Housing prices are included as the subprime meldown was at the epicentre of the GFC and more generally as their influence on the US business cycle is well documented (e.g. Leamer, 2007). Stock market shocks are important in their own right and also as they instantly

\footnotetext{
${ }^{4}$ In particular, it's a constructed index based on three components. The first component quantifies newspaper coverage of policy-related economic uncertainty. The second component reflects the number of federal tax code provisions set to expire in future years. The third component uses disagreement among economic forecasters as a proxy for uncertainty.
} 
reflect turmoil in other financial markets. Finally, EPU accounts for uncertainties, which affect economic decisions, all the more recently as the exceptional magnitude of the downturn has driven economic policies into uncharted territory. Innovations in output (proxied by industrial production) account for supply shocks, those in inflation for demand shocks and those in interest rates for monetary policy shocks.

We define $y_{t}=\left(E P U_{t}, r H r_{t}, r I P g r_{t}, I N F_{t}, r F T S E 100 r_{t}, D r I R_{t}\right)^{\prime}$ as the vector consisting of UK data on economic policy uncertainty, $E P U_{t}$, real housing market returns, $r H r_{t}$, real industrial production growth, $r I P g r_{t}$, inflation, $I N F_{t}$, real stock market returns, $r F T S E 100 r_{t}$, and real interest rate changes, $\operatorname{DrIR} R_{t}$, in year $t$.

Figure 1 and Table 1 illustrate and provide descriptive statistics on the underlying series in the United Kingdom.

\section{[Insert Figure 1 here] \\ [Insert Table 1 here]}

According to this figure, we observe that peaks of economic policy uncertainty tend to be associated with declining housing markets returns, industrial production growth and interest rate changes, real stock markets returns and inflation (especially during the global financial crisis). A feature which we explore further below.

Table 1 presents the descriptive statistics of our data. According to this table, we observe large variability in our main variables. The augmented Dickey-Fuller (ADF) test with just a constant, rejects the null hypothesis of a unit root for each series (i.e. all series are stationary), which motivates the use of a VAR model in these series.

\subsection{Empirical Methodology}

Our analysis is based on the spillover index approach introduced by Diebold and Yilmaz (2009, 2012); Diebold and Ylmaz (2014) which builds on the seminal work on VAR models by Sims (1980) and the notion of variance decompositions. It allows an assessment of the contributions of shocks to variables to their own forecast error variance and those of the other variables of the model. Using rolling-window estimation, the evolution of spillover effects can be traced over time and illustrated by spillover plots. 
The starting point for the analysis is the following $K^{\text {th }}$ order, $N$ variable VAR

$$
y_{t}=\sum_{k=1}^{K} \Theta_{k} y_{t-k}+\varepsilon_{t}
$$

where $y_{t}=\left(E P U_{t}, r H r_{t}, r I P g r_{t}, I N F_{t}, r F T S E 100 r_{t}, D r I R_{t}\right)^{\prime}$ is a vector of endogenous variables defined above; $\Theta_{k}, k=1, \ldots, K$, are $N \times N$ parameter matrices and $\varepsilon_{t} \sim(0, \Sigma)$ is a vector of disturbances that are assumed to be independently (though not necessarily identically) distributed over time; $t$ is the month index, ranging from 1997M1 to 2015M02.

Key to the dynamics of the system is the moving average representation of model (1), which is given by $y_{t}=\sum_{p=0}^{\infty} A_{p} \varepsilon_{t-p}$, where the $N \times N$ coefficient matrices $A_{p}$ are recursively defined as follows: $A_{p}=\Theta_{1} A_{p-1}+\Theta_{2} A_{p-2}+\ldots+\Theta_{p} A_{p-l}$, where $A_{0}$ is the $N \times N$ identity matrix and $A_{p}=0$ for $p<0$.

We use the variant of the spillover index in Diebold and Yilmaz (2012), which is based on the generalised VAR framework (Koop et al., 1996; Pesaran and Shin, 1998), in which forecast error variance decompositions are invariant to the ordering of the variables. Of course, this has advantages and drawbacks. Given our goal to assess the magnitude of macroeconomic spillovers (as determinants of (the share of) forecast error variances) rather than identifying the causal effects of structural shocks, this appears to be the preferred choice in the present context. ${ }^{5}$

In the generalised VAR framework, the $H$-step-ahead forecast error variance contribution is

$$
\phi_{i j}(H)=\frac{\sigma_{j j}^{-1} \sum_{h=0}^{H-1}\left(e_{i}^{\prime} A_{h} \Sigma e_{j}\right)^{2}}{\sum_{h=0}^{H-1}\left(e_{i}^{\prime} A_{h} \Sigma A_{h}^{\prime} e_{i}\right)},
$$

where $\Sigma$ is the (estimated) variance matrix of the error vector $\varepsilon, \sigma_{j j}$ the (estimated) standard deviation of the error term for variable $j$, and $e_{i}$ a selection vector with 1 as the $i^{t h}$ element and zeros otherwise. This yields a $6 \times 6$ matrix $\phi(H)=\left[\phi_{i j}(H)\right]_{i, j=1, \ldots, 6}$, where each entry gives the contribution of variable $j$ to the forecast error variance of variable $i$. The main diagonal elements contain the (own) contributions of shocks to variable $i$ to its own forecast error variance, the off-diagonal elements represent cross-variable spillovers,

\footnotetext{
${ }^{5}$ However, we explore the robustness of our results by using Cholesky factorization with alternative orderings of the variables, as discussed below, and our results remain very similar.
} 
defined here as contributions of other variables $j$ to the forecast error variance of variable $i$.

Since the own and cross-variable variance contribution shares do not sum to 1 under the generalised decomposition, i.e., $\sum_{j=1}^{N} \phi_{i j}(H) \neq 1$, each entry of the variance decomposition matrix is normalized by its row sum, such that

$$
\tilde{\phi}_{i j}(H)=\frac{\phi_{i j}(H)}{\sum_{j=1}^{N} \phi_{i j}(H)}
$$

with $\sum_{j=1}^{N} \tilde{\phi}_{i j}(H)=1$ and $\sum_{i, j=1}^{N} \tilde{\phi}_{i j}(H)=N$ by construction.

This ultimately allows to define a total spillover index, which is given by the following:

$$
T S(H)=\frac{\sum_{i, j=1, i \neq j}^{N} \tilde{\phi}_{i j}(H)}{\sum_{i, j=1}^{N} \tilde{\phi}_{i j}(H)} \times 100=\frac{\sum_{i, j=1, i \neq j}^{N} \tilde{\phi}_{i j}(H)}{N} \times 100
$$

which measures, on average over all variables, the contribution of spillovers from shocks to all other variables to the total forecast error variance.

This approach is quite flexible and allows to obtain a more differentiated picture by considering directional spillovers: Specifically, the directional spillovers received by variable $i$ from all other variables $j$ are defined as follows:

$$
D S_{i \leftarrow j}(H)=\frac{\sum_{j=1, j \neq i}^{N} \tilde{\phi}_{i j}(H)}{\sum_{i, j=1}^{N} \tilde{\phi}_{i j}(H)} \times 100=\frac{\sum_{j=1, j \neq i}^{N} \tilde{\phi}_{i j}(H)}{N} \times 100
$$

and the directional spillovers transmitted by variable $i$ to all other variables $j$ as follows:

$$
D S_{i \rightarrow j}(H)=\frac{\sum_{j=1, j \neq i}^{N} \tilde{\phi}_{j i}(N)}{\sum_{i, j=1}^{N} \tilde{\phi}_{j i}(H)} \times 100=\frac{\sum_{j=1, j \neq i}^{N} \tilde{\phi}_{j i}(H)}{N} \times 100 .
$$

Notice that the set of directional spillovers provides a decomposition of total spillovers into those coming from (or to) a particular variable.

By subtracting Equation (5) from Equation (6) the net spillovers from variable $i$ to all other variables $j$ are obtained as follows:

$$
N S_{i}(H)=D S_{i \rightarrow j}(H)-D S_{i \leftarrow j}(H)
$$

providing information on whether a variable is a receiver or transmitter of shocks in net terms. Put differently, Equation (7) provides summary information about how much each variable in the UK contributes to the other variables in net terms. 


\section{Empirical Findings}

In the following, we present the results from our empirical analysis. We start with the estimates of the static spillover index (i.e. an average estimate for the full sample period), and then consider the dynamic nature of spillovers using rolling window estimation.

\subsection{Spillover Indices}

Table 2 presents the estimation results for the spillover indices defined in Equations (4)(7), based on 12-month-ahead forecast error variance decompositions. Before discussing the results, let us first describe the structure and elements of Table 2. The $i j^{\text {th }}$ entry is the estimated contribution to the forecast error variance of variable $i$ coming from shocks (innovations) to variable $j$ (see Equation (2)). The diagonal elements $(i=j)$ measure intra-variable spillovers of shocks (over time), while the off-diagonal elements $(i \neq j)$ capture inter-variable (i.e., cross-variable) spillovers of shocks.

In addition, the row sums excluding the main diagonal elements (labelled 'Directional from others', see Equation (5)) report the total spillovers to (received by) the particular variable in the respective row, whereas the column sums (labelled 'Directional to others', see Equation (6)) report the total spillovers from (transmitted by) the particular variable in the respective column. The difference between each variable's (off-diagonal) column sum and the same variable's row sum gives the net spillovers of the respective variable to all other variables (see Equation (7)). Finally, the total spillover index defined in Equation (4), is given in the lower right corner of Table 2, is approximately equal to the grand off-diagonal column sum (or row sum) relative to the grand column sum including diagonals (or row sum including diagonals), expressed in percentage points. ${ }^{6}$

\section{[Insert Table 2 here]}

Table 2, that summarizes the average spillovers for the full sample period reveals several interesting regularities. First, intra-variable spillovers explain the highest share of forecast error variance, as the diagonal elements receive higher values compared with

\footnotetext{
${ }^{6}$ The approximate nature of the result is due to the fact that the contributions of the variables do not sum to 1 under the generalised decomposition framework and have to be normalized (see Equation (3)).
} 
the off-diagonal elements. For instance, innovations to real housing market returns in the United Kingdom explain $77.47 \%$ of the 12-month-ahead forecast error variance of real housing market returns in the United Kingdom, while $22.51 \%$ and $20.05 \%$ of the 12-month-ahead forecast error variance of inflation and real industrial production growth, respectively.

Second, the most important sources of net spillovers are real housing returns, stock market returns and inflation shocks. Housing price changes influence inflation, industrial production and the central banks interest rate. This is consistent with the well-known spillovers from housing prices to the wider economy, especially through residential investment as well as wealth and collateral effects on private consumption (Leamer, 2007; Lettau and Ludvigson, 2004; Case et al., 2005). Inflation also has an effect on housing prices, in particular through its effect on borrowing constraints. As they affect activity and inflation, variations in home prices also naturally tend to spill over to the policy rate (André et al., 2012). The largest spillover from stock market returns concerns the interest rate, which in turn increases economic policy uncertainty and the latter feeds back to the stock market. The variables receiving the largest net spillovers are industrial production, economic policy uncertainty and the interest rate, where the latter is adjusted according to economic and financial developments to stabilise the economy. Economic policy uncertainty is mostly affected by inflation, while industrial production is mainly impacted by the housing market and inflation. Stock market and housing market developments have a notable influence on the policy rate.

Third, according to the total spillover index reported at the lower right corner of Table 2, which effectively distils the various directional spillovers into one single index, on average, $34.93 \%$ of the forecast error variance in our set of variables comes from crossvariable spillovers of shocks in the UK.

Overall, the results reported in Table 2 suggest that, on average, both the total and directional spillovers across our set of variables are relatively high during our sample period, highlighting the interrelationships between the stock market, housing, policy uncertainty and the macroeconomy in the UK. 


\subsection{Spillover Plots}

While the average results for the full sample period in Table 2 are indicative, they might mask interesting changes in the pattern of inter-variable spillovers, given the long time span of three decades considered. Hence, we estimate the model in Equation (1) using 48month rolling windows and calculate the variance decompositions and spillover indices. ${ }^{7}$ As a result, we obtain time-varying estimates of spillover indices, allowing us to assess the intertemporal evolution of total and directional spillovers between the various variables in the model for the UK.

\section{[Insert Figure 2 here]}

Figure 2 presents the results for the time-varying total spillover index obtained from the 48-month rolling windows estimation. According to this figure, we observe a large variation in the total spillover index, which turns out very responsive to extreme economic events and closely associated with UK downturns of economic activity. In particular, the total spillover index reaches peaks during the UK recessions, the eurozone debt crisis, wars and geopolitical turmoil. During the global financial crisis, the total spillover index reached unprecedented levels. Overall, the index captures well spillovers from both domestic and external shocks.

Although the results for the total spillover index are informative, they might mask directional information that is contained in the "Directional to others" row (Equation (5)) and the "Directional from others" column (Equation (6)) in Table 2. Figure 3 presents the estimated 48-month rolling windows directional spillovers from each of the variables to others (corresponding to the "Directional to others" row in Table 2), while Figure 4 presents the estimated 48-month rolling windows directional spillovers from other variables to each variable (corresponding to the "Directional from others" column in Table 2).

[Insert Figure 3 here]

[Insert Figure 4 here]

\footnotetext{
${ }^{7}$ Our results reported below remain robust to alternative choices of window length (i.e. 60 and 72 months).
} 
According to these two figures, directional spillovers from or to each variable range between $4 \%$ and $40 \%$ and are of bidirectional nature. Nevertheless, they behave rather heterogeneously over time and follow a similar pattern as the one found for the total spillover index. That is, directional spillovers from or to each variable generally peak during extreme economic events, such as housing bubble bursting and the global financial crisis. Spillovers from variables show more volatility than spillovers to them, suggesting that the impact of specific shocks tend to partially offset each other, reflecting stabilising forces in the economy. Spillovers to interest rates and EPU vary the most over time, which could be expected from a policy instrument and policy related variable.

Net directional spillover indices obtained from the 48-month rolling window estimation show which shocks have caused most volatility in the economy at specific points in time. According to Figure 5, which plots the time-varying net directional spillovers across variables, we observe that all variables frequently switch between a net transmitting and a net receiving role. Most notable over the sample period are: the large spillovers from inflation in the mid-2006, followed by the dominance of industrial production growth shock spillovers in the period preceding the global financial crisis. During the global financial crisis, the dominance of the net transmitting role of shocks in the stock market, the increased economic policy uncertainty and the monetary policy responses to alleviate the crisis are observed. These development affected substantially the housing market, with housing market returns shocks capturing the dominant role of spillovers of shocks between the period of 2009 and 2014. Overall, these results highlight the importance of spillovers and the feedback effects of the various sectors and their destabilising impact in the UK.

\section{[Insert Figure 5 here]}

We now turn our attention to the results of the net pairwise directional spillovers indices obtained from the 48-month rolling window estimation so as to determine which shocks caused the most volatility in each of the other variables considered in this study. Figure 6 synthetically display the main results for our dynamic analysis of the net pairwise directional spillovers/connectedness for the full, and the pre- and post-global financial cri- 
sis (GFC) sample, focusing on cases where the intensity was especially significant. ${ }^{8}$ That is, we provide a visualization of the complex network of innovation overflows among the six variables in our sample. The colour of the arrows indicates the intensity of spillovers among the variables. According to this figure, for the full sample, the housing market plays a dominant role in the transmission and amplification of shocks in the UK. In particular, housing market shocks are being transmitted to industrial production growth, stock market returns and inflation. Innovations in the stock market also spill over to industrial production growth and inflation, and trigger strong monetary policy responses (changes in the interest rates) to stabilise the UK economy. In the pre-GFC period, shocks in the housing market are being transmitted to the stock market, which, in turn, are being transmitted to industrial production growth and interest rates. Industrial production growth shocks also trigger policy responses, while inflationary shocks intensify economic policy uncertainty. Finally, in the post-GFC period, the dominant role of the housing market and financial crises to the real economy, as well as the policy responses, are again evident. Specifically, the housing market plays a dominant role in the transmission process of shocks to industrial production growth, inflation and interest rates. Stock markets shocks contribute also to a large extent to industrial production growth and inflation uncertainty, while inflationary shocks are being transmitted to industrial production growth and also affected by innovations in economic policy uncertainty.

\section{[Insert Figure 6 here]}

Overall, these results illustrate the contagion from the housing and financial crisis to the real economy and the strong policy reaction to stabilise the UK economy.

\subsection{Impulse responses}

In this section, we present the generalised impulse responses of the various shocks in the UK. Figure 7 exhibits these 12-month ahead impulse responses of a one standard deviation shocks in the variables consider in this model.

\footnotetext{
${ }^{8}$ The full results of the dynamic net pairwise directional spillovers are presented in the A.1 in the Appendix.
} 
[Insert Figure 7 here]

According to this figure, economic policy uncertainty shocks significantly reduce housing market returns, and cause short-lived reductions in industrial production growth, stock market returns and interest rate changes, while short-lived increases in inflation. The impact of positive housing market shocks reduces economic policy uncertainty, leads to positive industrial production growth and positive interest rate changes. A short-lived decline in inflation and an insignificant increase in stock market returns is observed following a positive housing market return shock. Turing to the impact of positive industrial production growth shocks, we observe a negative impact on economic policy uncertainty and inflation, while a positive impact on housing market returns, stock market returns and interest rates changes. Inflation shocks lead to significant increases in policy uncertainty, reductions in housing market returns and industrial production growth and an instantaneous negative interest rate change. Positive stock market shocks lead to reduced economic policy uncertainty, increased housing market returns and interest rate changes, while short-lived increases in industrial production growth and inflation. Finally, positive interest rate changes shocks increase economic policy uncertainty, cause shortlived increases in housing market returns, stock market returns and industrial production growth, and an instantaneous reduction in inflation followed by another short-lived increase in inflation in one month ahead the interest rate shock.

\subsection{Robustness analysis}

In an attempt to check the robustness of the results obtained based on the generalised version of the spillover index by Diebold and Yilmaz (2012), we also employ the spillover index approach of Diebold and Yilmaz (2009), which is based on the Cholesky decomposition and in which the forecast error variance decomposition is sensitive to the ordering of the variables in the VAR. In particular, we analyse 100 random permutations (different orderings of the variables in the VAR) and construct the corresponding spillover indices for each ordering. Figure 8 presents the minimum and maximum values that the total spillover index receives based on Cholesky factorization. According to this figure, the results are in line with those of our main approach reported in Figure 2. In particular, 
the spillover index varies between $35 \%$ and $75 \%$ and reaches a peak during (extreme) economic events identified in the baseline analysis.

\section{[Insert Figure 8 here]}

Finally, we examine the robustness of our results by estimating alternative rolling window samples. In particular, we estimate the model with 60-month and 72-month rolling windows, in addition to 48-month rolling windows, and present the minimum and maximum values of the dynamic total spillover index in Figure 9. According to this figure, the use of alternative rolling window sample does not affect our main conclusions reached above.

\section{[Insert Figure 9 here]}

\section{Conclusions}

According to Maclennan (1994) “... the housing market is a large sector of the economy and it is highly possible that the housing market and the economy interact. Although the feedback mechanism is possible, it is not very clear". The study of housing market is of particular relevance due to the importance of the housing sector to the global economy (Stevenson, 1999). For example, the combination of tightening credit, increasing pressure on consumer expenditure and falling property prices will have an impact on the economy; the correct policy response to real estate booms (Crowe et al., 2013).

Understanding the determinants of house prices is crucial for investors and policy makers (Pan and Wang, 2013). The determinants of house prices include factors that drive the demand for and supply of housing, such as population, income, interest rates, availability of mortgage financing, and house price growth expectations (housing demand) and house prices, construction costs, and the availability of financing (housing supply). However, housing has unique characteristics, and therefore, the real estate market is affected by economic uncertainty. The collapse of the subprime residential mortgage market in the US was the catalyst for the global financial crisis.

This study provides a detailed examination on the dynamic interdependencies among housing market, stock market, policy uncertainty and key macroeconomic variables for 
UK over the period January 1997 to February 2015. Prior to the financial crisis, the UK had experienced housing booms. In particular, UK house prices have risen by an average of $187 \%$ across the UK since the housing market recovered in February 1996, while stock prices rose just $61 \%$ that period. UK house prices fell by $2.5 \%$ in March 2008. The ongoing uncertainty in the financial markets has fuelled turmoil in investment markets. Since the September 2008 financial crisis, the UK property market fell dramatically due to an increased uncertainty in global economic conditions and increased volatility of investment markets.

Our main contribution actually lies in the examination of UK factors driving and being driven by house prices. Interesting questions naturally arise on this topic are: Is there a transmission of various types of shocks that contributes significantly to economic fluctuations in the United Kingdom? What is the level of spillovers from/to housing market to/from other key variables? Do UK house prices and stock market show a contagion to the real economy?

Based on UK monthly data over the period 1997M1-2015M02, our findings reveal the following empirical regularities. First, the transmission of various types of shocks contributes significantly to economic fluctuations in the United Kingdom. Second, spillovers show large variations over time. Third, in the wake of the global financial crisis, spillovers have reached unprecedented levels. Specifically, we find large spillovers from the housing market, stock market and economic policy uncertainty to other variables, in particular inflation, industrial production, and the interest rate. These results illustrate the contagion from the housing and financial crisis to the real economy and the policy reaction to stabilise the economy. The reported dynamic linkages in our study are in line with Beltratti and Morana (2010) for G-7 international house prices, while the spillover effects are in accordance with Cesa-Bianchi (2013). Finally, we confirm the contagion between stock and real estate markets reported by Chan et al. (2011).

These results may be of interest to policy-makers, who should take into consideration the spillover effects explained by the dynamic interdependencies among these variables. According to (Crowe et al., 2013, p. 58), "the main risks from real estate boom-busts come from increased leverage in both the real (in particular, households) and financial sectors. 
Then policies should, whenever possible, aim at containing these risks rather than price increases. In that context, policies should target two, non-mutually exclusive objectives: (i) preventing real estate booms and the associated leverage build-up altogether, and (ii) increasing the resilience of the financial system to a real estate bust". Financial managers and policy makers should understand the synergies and connectivity that exist between real estate and financial institutions and between the financial markets and the economy.

Further research along these lines is called upon to examine the interdependencies between housing prices and economic variables using regional data from Europe.

\section{References}

Adams, Z., Füss, R., 2010. Macroeconomic determinants of international housing markets. Journal of Housing Economics 19 (1), 38-50.

Agnello, L., Schuknecht, L., 2011. Booms and busts in housing markets: Determinants and implications. Journal of Housing Economics 20 (3), 171-190.

André, C., Gupta, R., Kanda, P. T., 2012. Do House Prices Impact Consumption and Interest Rate? Evidence from OECD Countries using an Agnostic Identification Procedure. Applied Economics Quarterly 58 (1), 19-70.

Apergis, N., Lambrinidis, L., 2011. More evidence on the relationship between the stock and the real estate market. Briefing Notes in Economics 85, 1-18.

Baker, S., Bloom, N., Davis, S., 2012. Measuring Economic Policy Uncertainty. Working Paper Series, Stanford University.

Beltratti, A., Morana, C., 2010. International house prices and macroeconomic fluctuations. Journal of Banking \& Finance 34 (3), 533-545.

Bernanke, B., Boivin, J., Eliasz, P. S., 2005. Measuring the effects of monetary policy: A factor-augmented vector autoregressive (FAVAR) approach. The Quarterly Journal of Economics 120 (1), 387-422.

Bouchouicha, R., Ftiti, Z., 2012. Real estate markets and the macroeconomy: A dynamic coherence framework. Economic Modelling 29 (5), 1820-1829.

Brooks, C., Tsolacos, S., 1999. The impact of economic and financial factors on UK property performance. Journal of Property Research 16 (2), 139-152.

Brunnermeier, M. K., Julliard, C., 2008. Money illusion and housing frenzies. Review of Financial Studies 21 (1), 135-180.

Calza, A., Monacelli, T., Stracca, L., 2013. Housing finance and monetary policy. Journal of the European Economic Association 11, 101-122. 
Case, K. E., Quigley, J. M., Shiller, R. J., 2005. Comparing Wealth Effects: The Stock Market versus the Housing Market. The B.E. Journal of Macroeconomics 5 (1), 1-34.

Cesa-Bianchi, A., 2013. Housing cycles and macroeconomic fluctuations: A global perspective. Journal of International Money and Finance 37 (C), 215-238.

Chan, K. F., Treepongkaruna, S., Brooks, R., Gray, S., 2011. Asset market linkages: Evidence from financial, commodity and real estate assets. Journal of Banking \& Finance 35 (6), 1415-1426.

Crowe, C., Dell'Ariccia, G., Igan, D., Rabanal, P., 2013. How to deal with real estate booms: Lessons from country experiences. Journal of Financial Stability 9 (3), 300-319.

Davis, M. A., Nieuwerburgh, S. V., 2015. Housing, Finance, and the Macroeconomy, in Handbook of Regional and Urban Economics. Vol. 5B. Elsevier, Ch. 12, pp. 753-809.

Diebold, F. X., Yilmaz, K., 2009. Measuring Financial Asset Return and Volatility Spillovers, with Application to Global Equity Markets. Economic Journal 119 (534), 158-171.

Diebold, F. X., Yilmaz, K., 2012. Better to Give than to Receive: Predictive Directional Measurement of Volatility Spillovers. International Journal of Forecasting 28 (1), 57-66.

Diebold, F. X., Ylmaz, K., 2014. On the Network Topology of Variance Decompositions: Measuring the Connectedness of Financial Firms. Journal of Econometrics 182 (1), 119-134.

Englund, P., Ioannides, Y. M., 1997. House price dynamics: An international empirical perspective. Journal of Housing Economics 6 (2), 119-136.

Goodhart, C., Hofmann, B., 2008. House prices, money, credit, and the macroeconomy. Oxford Review of Economic Policy 24 (1), 180-205.

Heaney, R., Sriananthakumar, S., 2012. Time-varying correlation between stock market returns and real estate returns. Journal of Empirical Finance 19 (4), 583-594.

Higgins, D. M., September 2007. Placing commercial property in the Australian capital market. Tech. Rep. 12, RICS Research paper series.

Himmelberg, C., Mayer, C., Sinai, T., 2005. Assessing high house prices: Bubbles, fundamentals and misperceptions. Journal of Economic Perspectives 19 (4), 67-92.

Hwang, M., Quigley, J. M., 2006. Economic fundamentals in local housing markets: Evidence from U.S. metropolitan regions. Journal of Regional Science 46 (3), 425-453.

Iacoviello, M., 2005. House prices, borrowing constraints, and monetary policy in the business cycle. American Economic Review 95 (3), 739-764.

Iacoviello, M., Minetti, R., 2003. Financial liberalization and the sensitivity of house prices to monetary policy: Theory and evidence. Manchester School 71 (1), 20-34.

Koop, G., Pesaran, M. H., Potter, S. M., 1996. Impulse Response Analysis in Nonlinear Multivariate Models. Journal of Econometrics 74 (1), 119-147.

Leamer, E. E., 2007. Housing is the Business Cycle. Proceedings -Economic Policy Symposium- Jackson Hole, Federal Reserve Bank of Kansas City, 149-233. 
Lettau, M., Ludvigson, S. C., 2004. Understanding Trend and Cycle in Asset Values: Reevaluating the Wealth Effect on Consumption. American Economic Review 94 (1), 276-299.

Leung, C., 2004. Macroeconomics and housing: A review of the literature. Journal of Housing Economics $13(4), 249-267$.

Lin, T. C., Lin, Z.-H., 2011. Are stock and real estate markets integrated? An empirical study of six Asian economies. Pacific-Basin Finance Journal 19 (5), 571-585.

Ling, D. C., Naranjo, A., 1999. The integration of commercial real estate markets and stock markets. Real Estate Economics 27 (3), 483-515.

Liu, C. H., Hartzell, D. J., Greig, W., Grissom, T. V., 1990. The integration of the real estate market and the stock market: Some preliminary evidence. The Journal of Real Estate Finance and Economics $3(3), 261-282$.

Lizieri, C., Satchell, S., 1997. Interactions between Property and Equity Markets: An Investigation of Linkages in the United Kingdom 1972-1992. The Journal of Real Estate Finance and Economics 15 (1), $11-26$.

Maclennan, D., 1994. A Competitive UK Economy: Challenges for Housing Policy. New York: Joseph Rowntree Foundation.

McQuinn, K., O’Reilly, G., 2008. Assessing the role of income and interest rates in determining house prices. Economic Modelling 25 (3), 377-390.

Miles, M., Cole, R., Guilkey, D., 1990. A different look at commercial real estate returns. Real Estate Economics 18 (4), 403-430.

Nneji, O., Brooks, C., Ward, C. W., 2013. House price dynamics and their reaction to macroeconomic changes. Economic Modelling 32 (C), 172-178.

Okunev, J., Wilson, P., Zurbruegg, R., 2002. Relationships between Australian real estate and stock market prices - A case of market inefficiency. Journal of Forecasting 21 (3), 181-192.

Pan, H., Wang, C., 2013. House prices, bank instability, and economic growth: Evidence from the threshold model. Journal of Banking \& Finance 37 (5), 1720-1732.

Pesaran, H. H., Shin, Y., 1998. Generalized Impulse Response Analysis in Linear Multivariate Models. Economics Letters 58 (1), 17-29.

Quan, D. C., Titman, S., 1999. Do real estate prices and stock prices move together? An international analysis. Real Estate Economics 27 (2), 183-207.

Schindler, F., 2014. Persistence and predictability in UK house price movements. The Journal of Real Estate Finance and Economics 48 (1), 132-163.

Sims, C., 1980. Macroeconomics and Reality. Econometrica 48, 1-48.

Stevenson, S., 1999. The performance and inflation hedging ability of regional housing markets. Journal of Property Investment 8 Finance 17 (3), 239-260.

Tse, C.-B., Rodgers, T., Niklewski, J., 2014. The 2007 financial crisis and the UK residential housing 
market: Did the relationship between interest rates and house prices change? Economic Modelling 37 (C), 518-530.

Tse, R. Y. C., 2001. Impact of property prices on stock prices in hong kong. Review of Pacific Basin Financial Markets and Policies 04 (01), 29-43.

Table 1: Descriptive statistics

\begin{tabular}{lcccccc}
\hline \hline & EPU & rHousing returns & rIP growth & Inflation & rFTSE00r & DrIR \\
\hline Min & 25.94 & -22.492 & -14.915 & 0.0314 & -50.125 & -1.3604 \\
Mean & 130.28 & 4.6594 & -2.6644 & 2.0708 & 0.0945 & -0.0291 \\
Max & 408.75 & 22.152 & 3.0363 & 5.0797 & 36.614 & 0.3273 \\
Std & 82.924 & 8.8107 & 3.4060 & 1.0251 & 16.244 & 0.1816 \\
$\mathrm{ADF}^{a}$ (constant) & $-3.476^{* *}$ & $-3.212^{*}$ & $-3.012^{*}$ & $-3.104^{*}$ & $-3.104^{*}$ & $-7.686^{* *}$ \\
\hline \hline
\end{tabular}

Note: ${ }^{a}$ The $5 \%$ and $1 \%$ critical values are -2.88 and -3.46 , respectively. ${ }^{*}$ and ${ }^{* *}$ indicate significance at $5 \%$ and $1 \%$ level, respectively. 
Table 2: Estimation Results for Spillover Indices

\begin{tabular}{lccccccc}
\hline \hline & \multicolumn{7}{c}{$(j)$} \\
\cline { 2 - 8 } & & & & & & & \\
(i) & EPU & rHr & rIPgr & INF & rFTSE100r DrIR & from others \\
\hline EPU & 71.93 & 1.45 & 2.50 & 14.35 & 2.28 & 7.49 & 28.07 \\
rHr & 0.55 & 77.47 & 0.51 & 15.05 & 1.44 & 4.98 & 22.53 \\
rIPgr & 0.37 & 20.05 & 36.55 & 21.28 & 18.07 & 3.68 & 63.45 \\
INF & 0.09 & 22.51 & 2.21 & 62.49 & 10.54 & 2.16 & 37.51 \\
rFTSE100r & 3.60 & 3.11 & 3.19 & 10.39 & 77.66 & 2.04 & 22.34 \\
DrIR & 0.17 & 10.43 & 1.01 & 2.50 & 21.58 & 64.31 & 35.69 \\
\hline Dir. to others & 4.79 & 57.54 & 9.43 & 63.58 & 53.91 & 20.35 & Total Spillover \\
Dir. including own & 76.72 & 135.01 & 45.98 & 126.07 & 131.57 & 84.66 & Index $=34.93 \%$ \\
Net dir. spillovers & -23.28 & 35.01 & -54.02 & 26.07 & 31.57 & -15.34 & \\
\hline \hline
\end{tabular}

Notes: The underlying variance decomposition is based upon a monthly VAR of order 3 . The number of lags (3) have been selected based on the Akaike Information Criterion (AIC) and the Bayesian Information Criterion (BIC). Spillover indices, given by Equations (2)-(7), calculated from variance decompositions based on 12-month ahead forecasts. 
Figure 1: EPU, housing market returns, output growth, inflation, stock market returns and interest rates
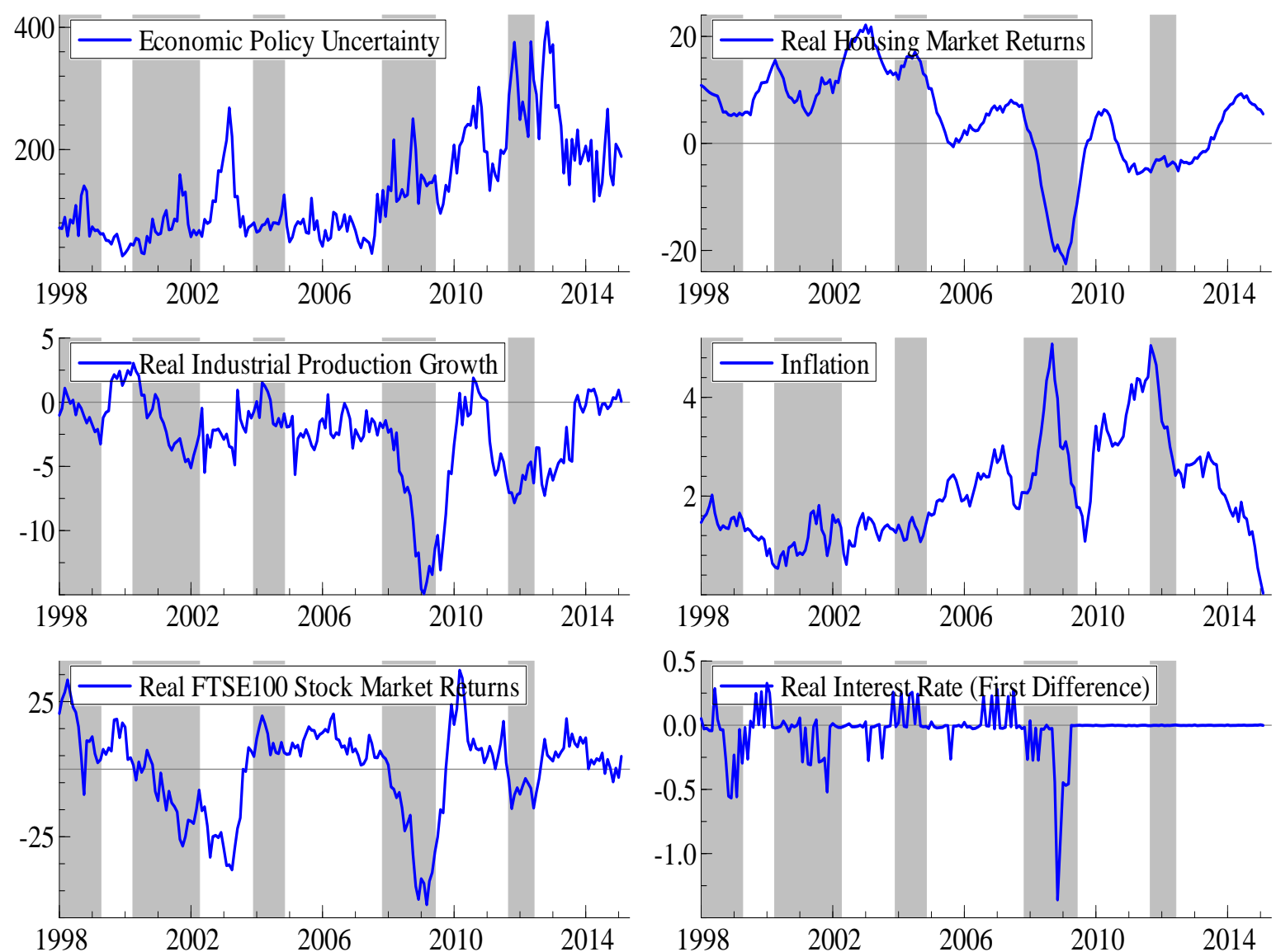

Notes: Grey shading denotes UK recessions as defined by OECD. 
Figure 2: Total spillover index of EPU, housing market returns, output growth, inflation, stock market returns and interest rates

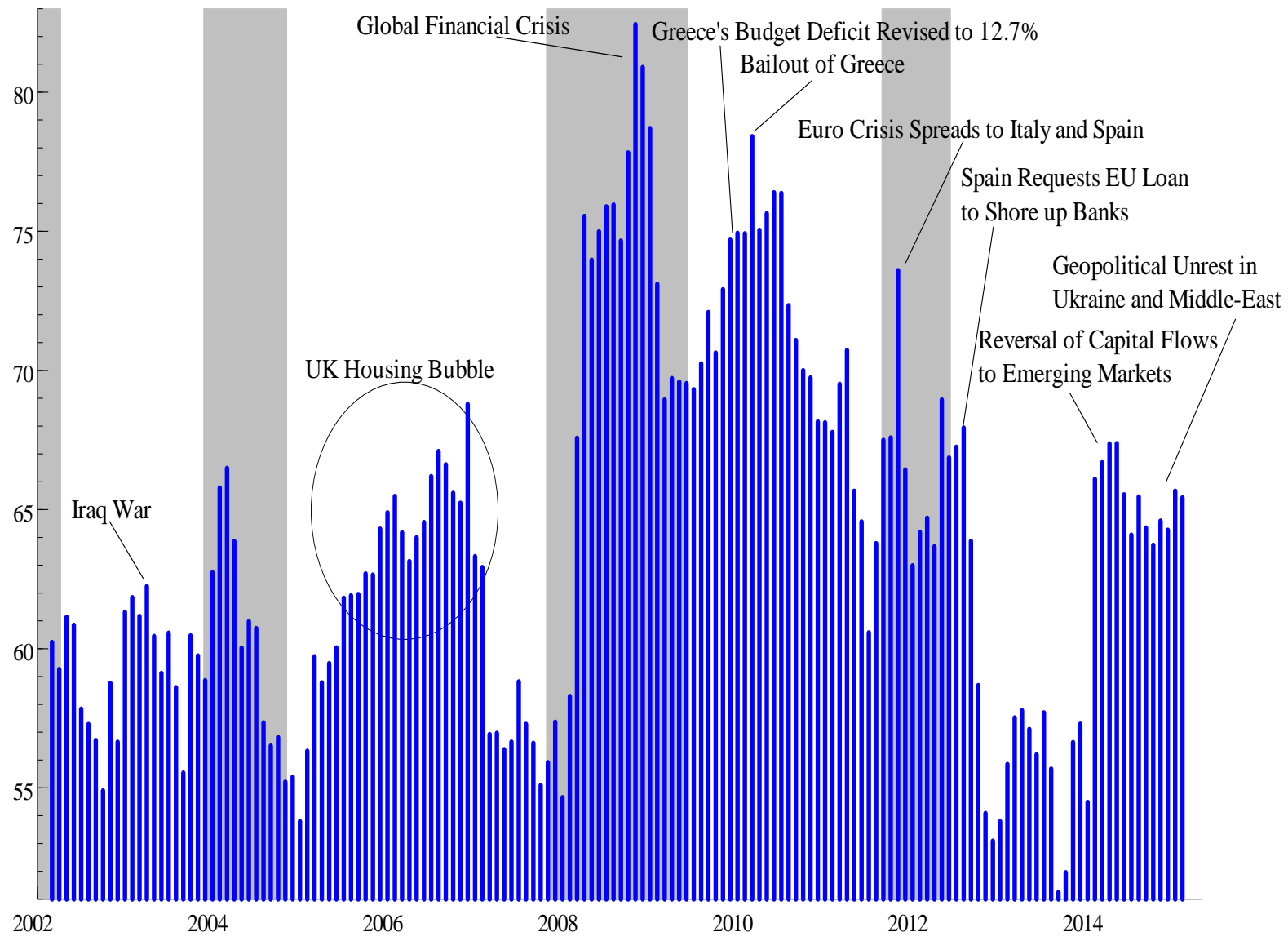

Notes: Plot of moving total spillover index estimated using 60-month rolling windows (and hence starting in 2002M3). Grey shading denotes UK recessions as defined by OECD. 
Figure 3: Directional spillovers from EPU, housing market returns, output growth, inflation, stock market returns and interest rates
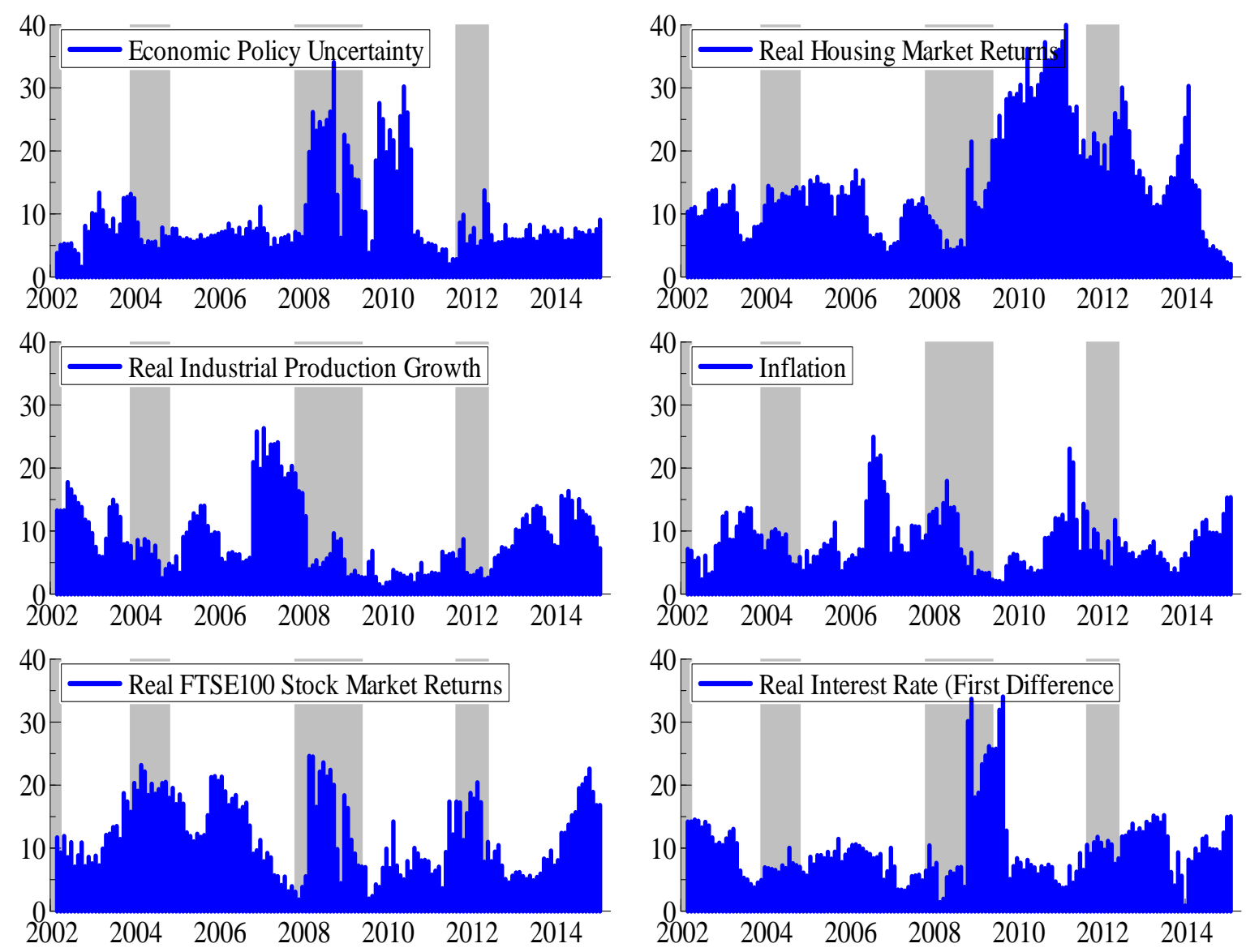

Notes: Plots of moving directional spillover indices estimated using 48-month rolling windows. Grey shading denotes UK recessions as defined by OECD. 
Figure 4: Directional spillovers to EPU, housing market returns, output growth, inflation, stock market returns and interest rates
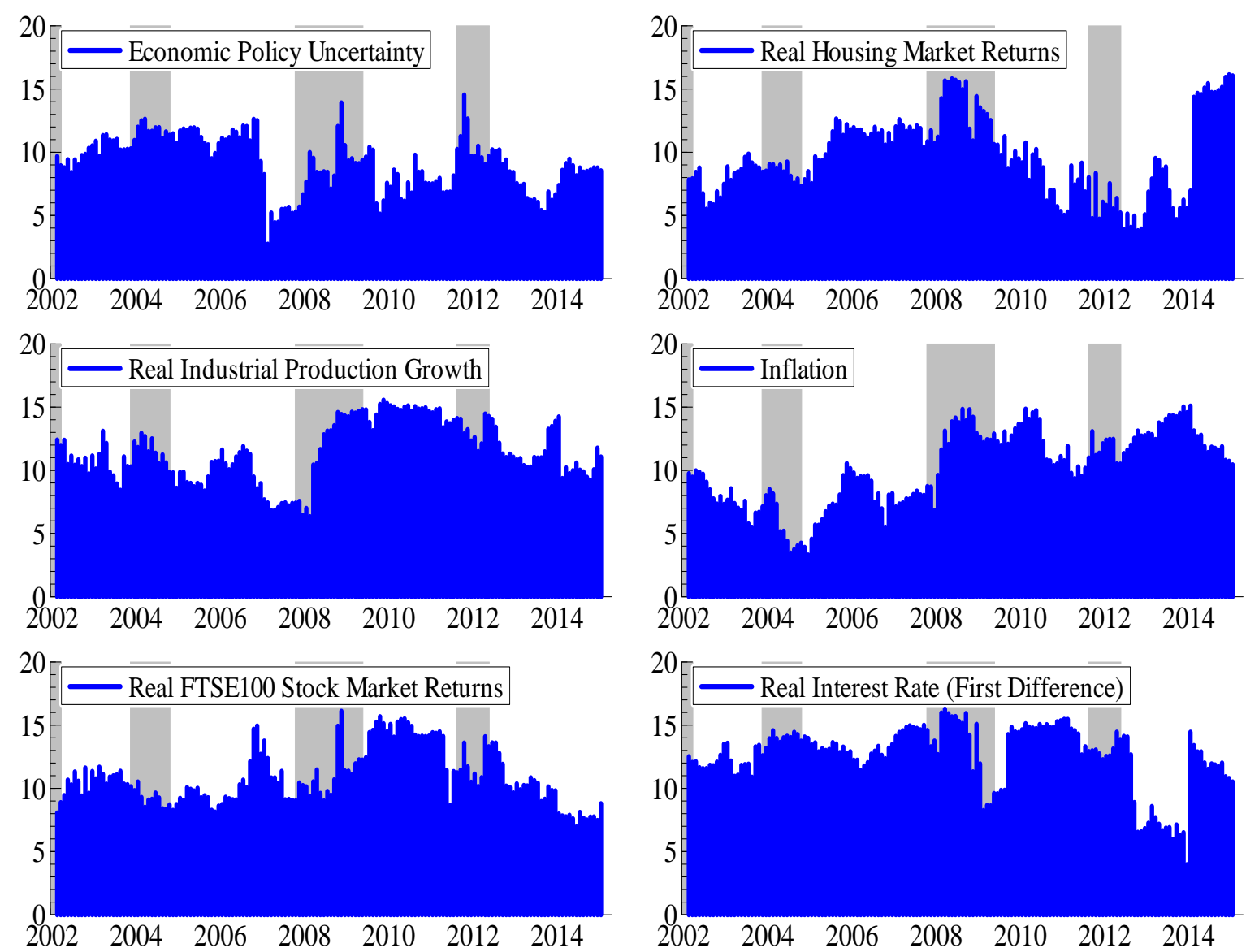

Notes: Plots of moving directional spillover indices estimated using 48-month rolling windows. Grey shading denotes UK recessions as defined by OECD. 
Figure 5: Net directional spillovers of EPU, housing market returns, output growth, inflation, stock market returns and interest rates
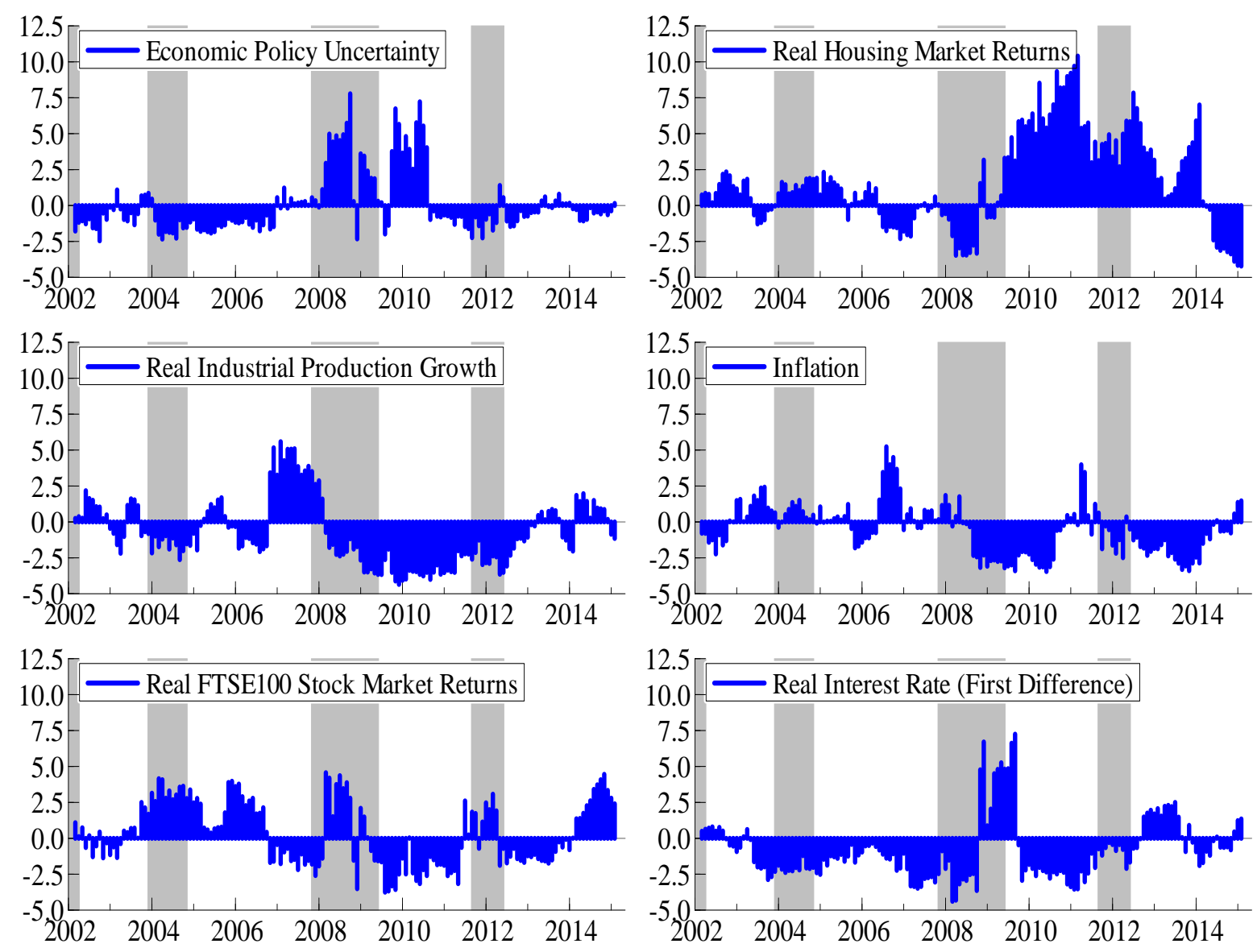

Notes: Plot of moving net directional spillover indices estimated using 48-month rolling windows. Grey shading denotes UK recessions as defined by OECD. 
Figure 6: Net directional pairwise spillovers/connectedness of EPU, housing market returns, output growth, inflation, stock market returns and interest rates
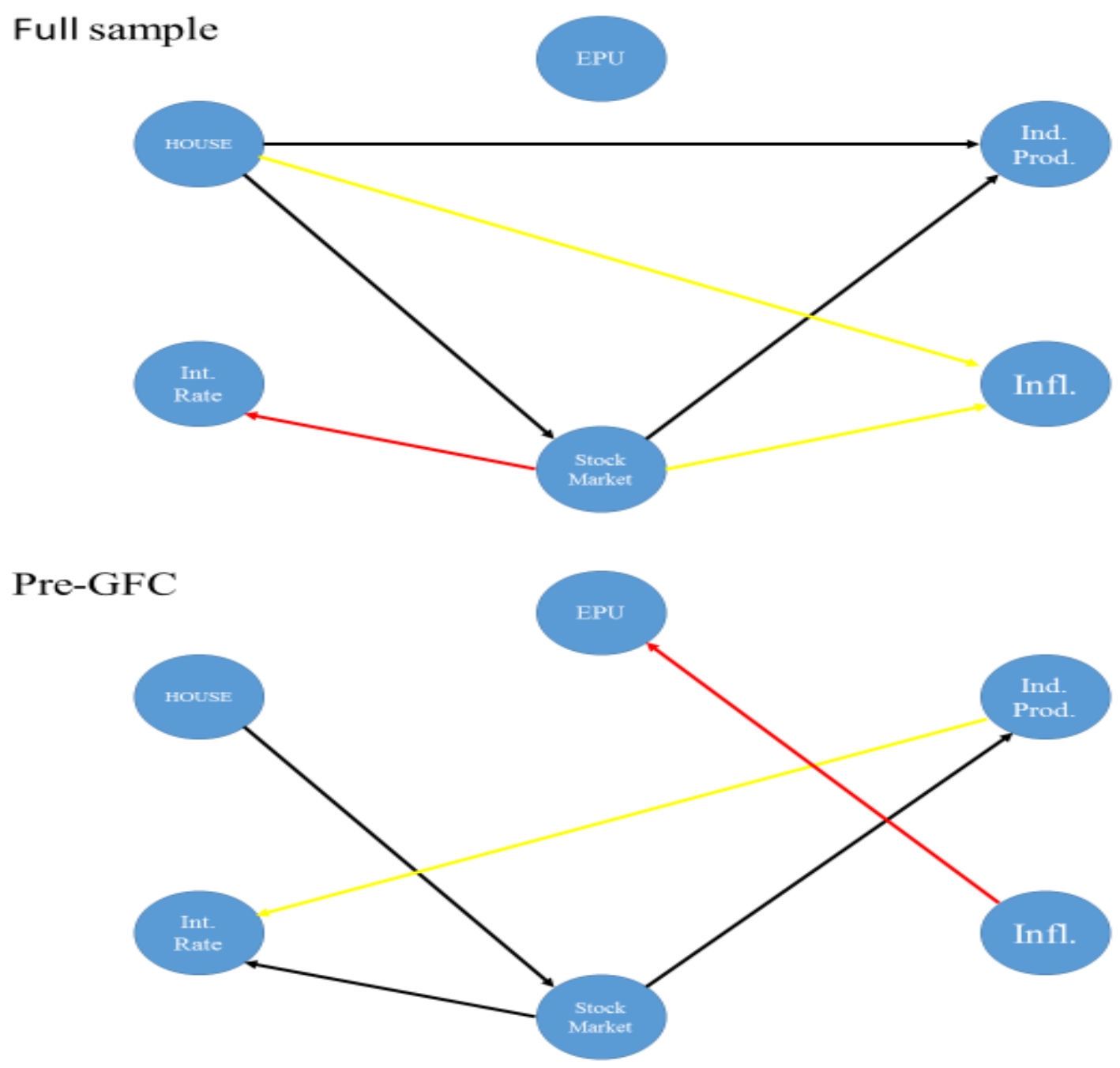

\section{Post-GFC}

\section{EPU}

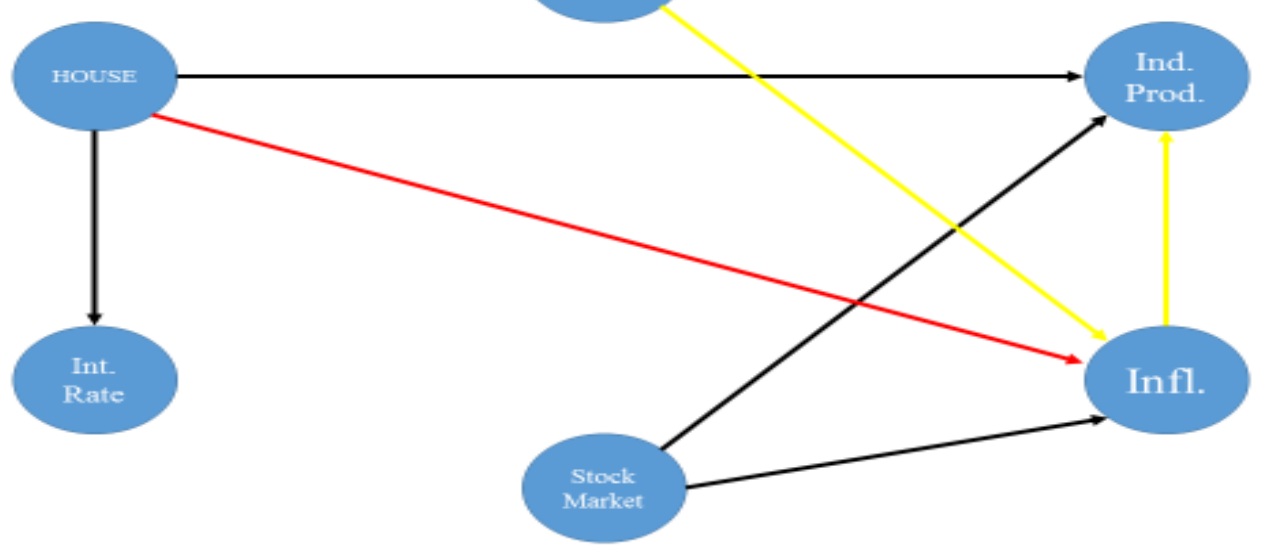

Notes: We show the most important directional congections between the 15 pairs of the variables under study. Black, red and yellow links (black, grey and light grey when viewed in grey scale) correspond, respectively, to the cases where we detect a net pair-wise directional connection in $64-75 \%, 76-87 \%$ and 88-100\% of the sample. EPU, House, Ind. Prod. Infl. Stock Market and Interest rates stand for economic 
Figure 7: Generalised impulse responses to economic uncertainty, housing market returns, industrial production, inflation, stock market returns and interest rate shocks
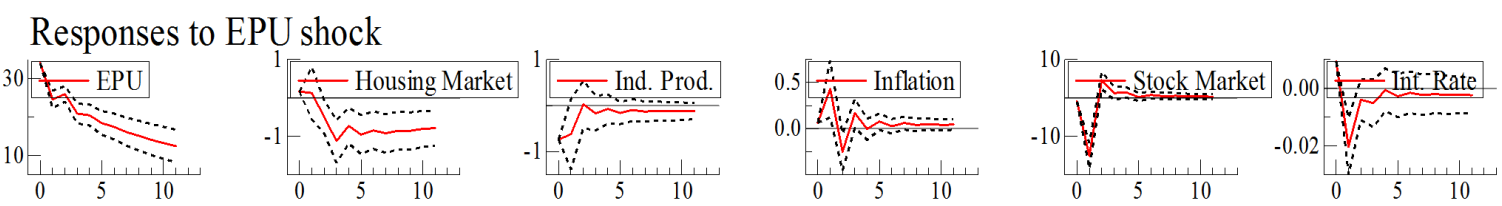

Responses to Housing Market shock
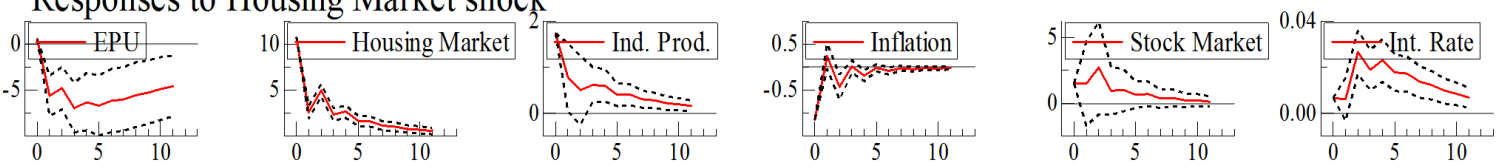

Responses to Industrial Production shock
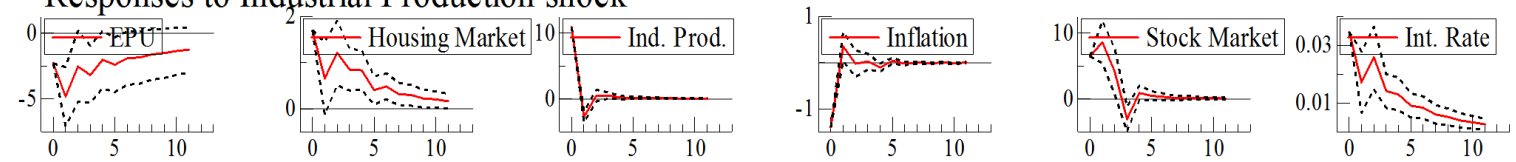

Responses to Inflation shock
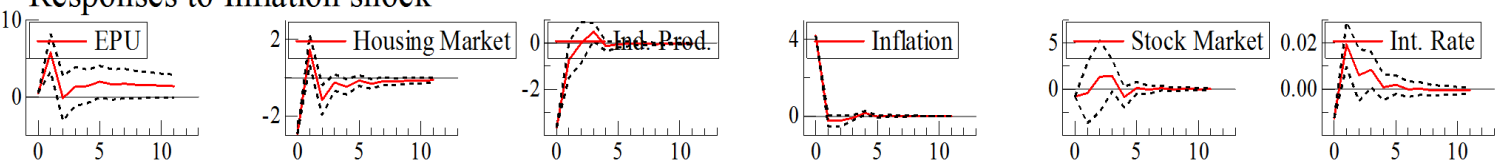

Responses to Stock Market shock
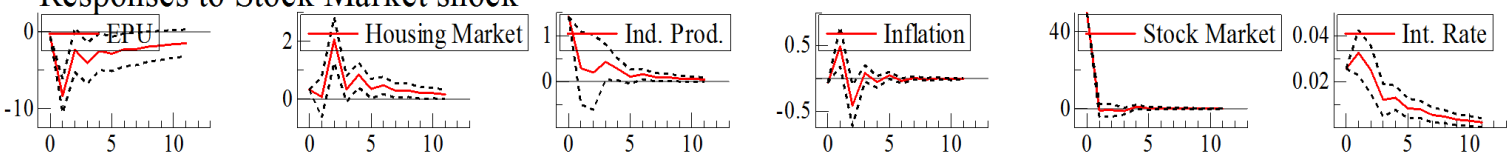

Responses to Interest Rate shock
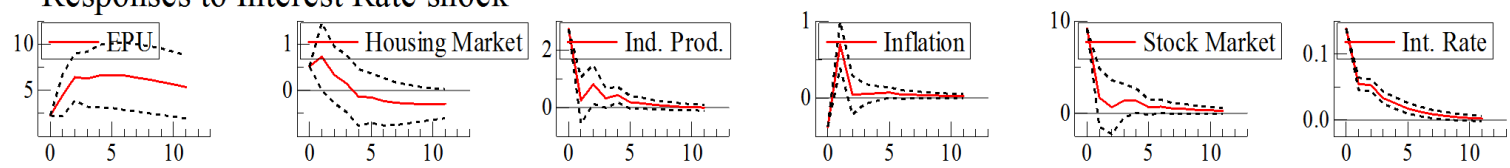

Notes: Dotted lines denote upper and lower bounds (0.16 and 0.84 percentiles) constructed using Monte Carlo integration based on 1000 draws. 
Figure 8: Maximum and minimum total spillovers based on Cholesky factorization with random permutations

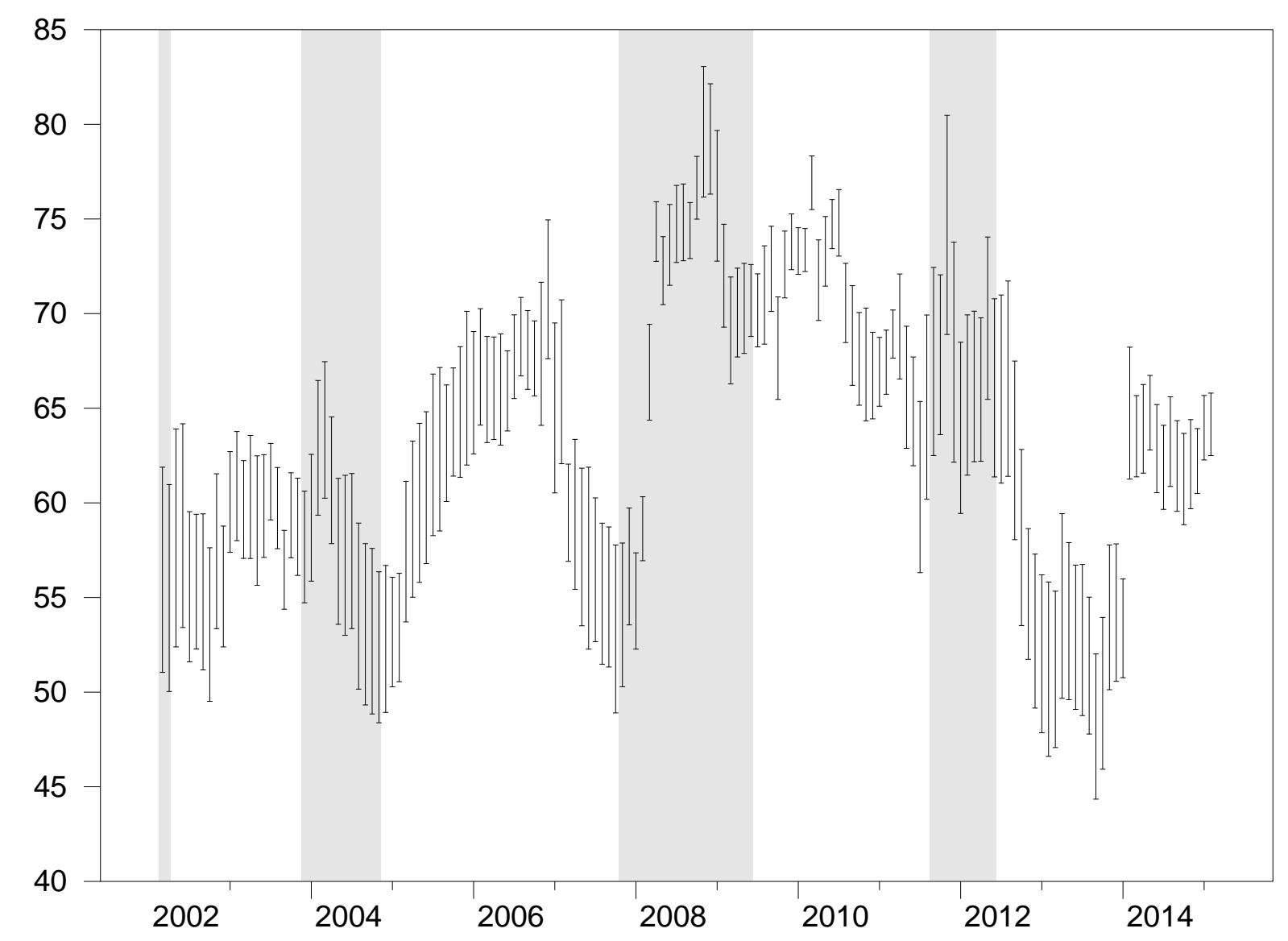

Notes: Plot of maximum and minimum dynamic total spillover index estimated based on Cholesky factorization with 100 randomly chosen orderings using 48-month rolling windows. Grey shading denotes UK recessions as defined by OECD. 
Figure 9: Total spillovers with alternative rolling window samples

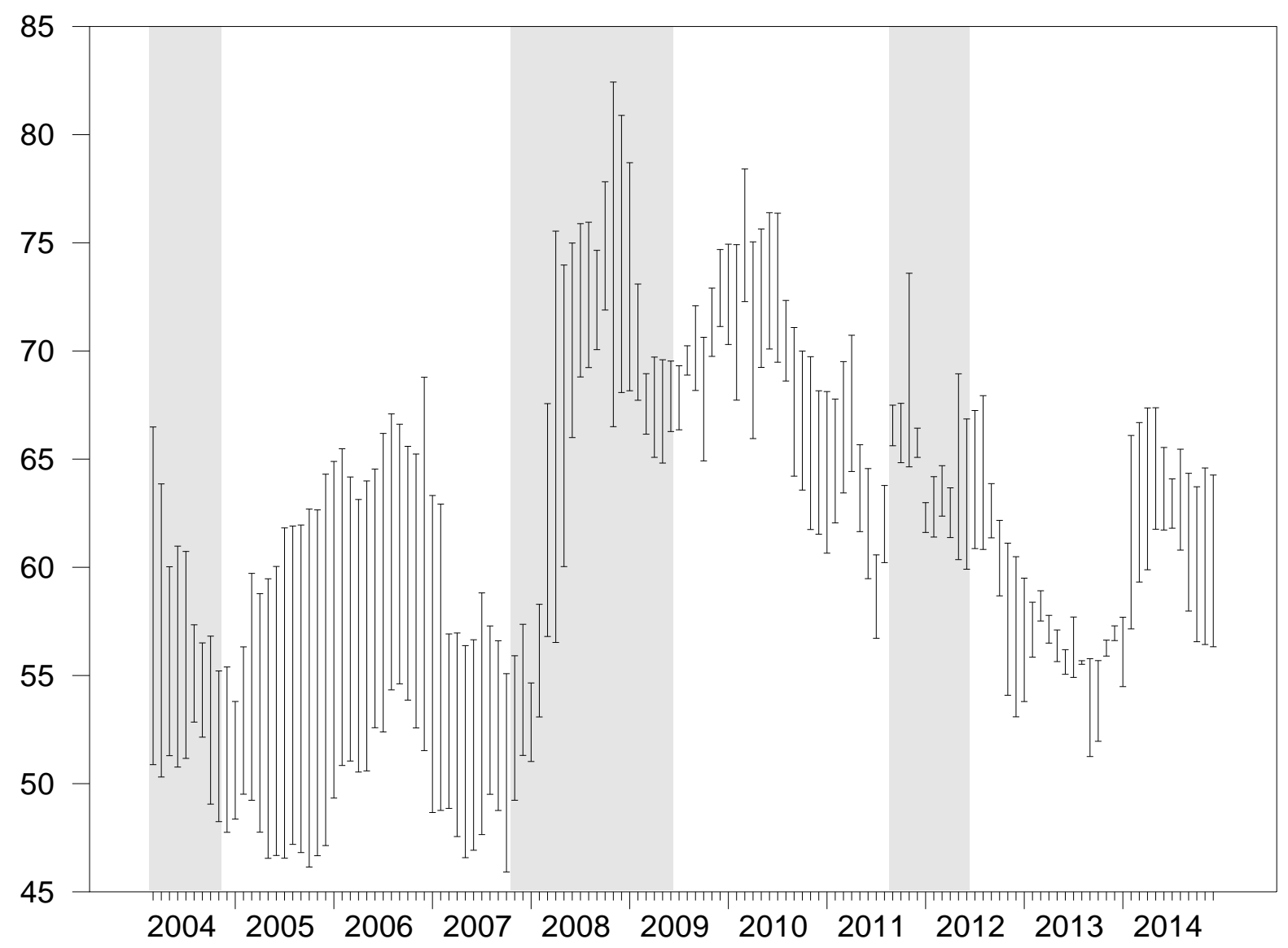

Note: Plot of dynamic total spillover index estimated using 48-month (4-year), 60-months (5-year) and 72-months (6-year) rolling windows. Grey shading denotes UK recessions as defined by OECD. 


\section{Appendix}

Figure A.1: Net directional pairwise spillovers of EPU, housing market returns, output growth, inflation, stock market returns and interest rates
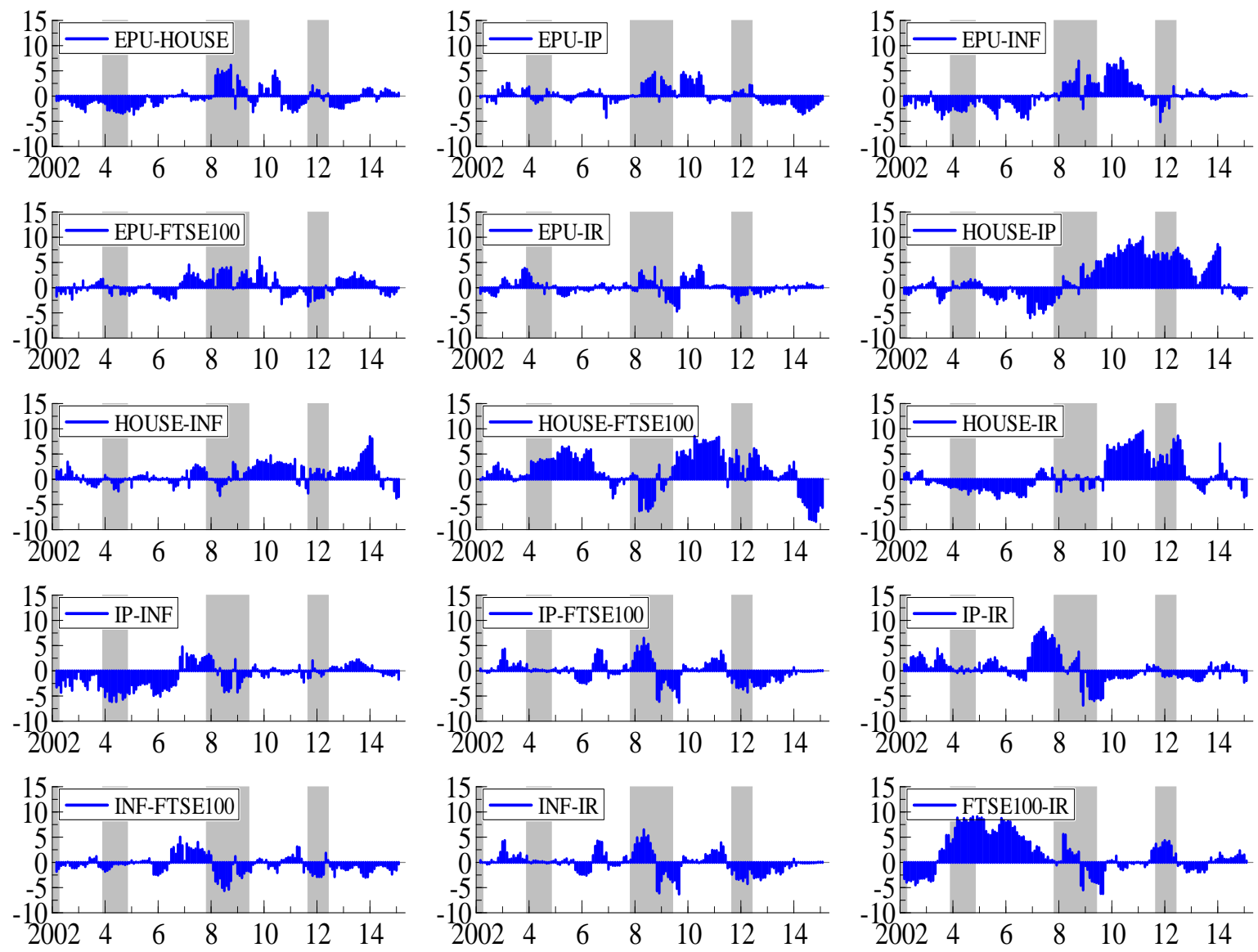

Notes: Plot of moving net directional pairwise spillover indices estimated using 48-month rolling windows. Grey shading denotes UK recessions as defined by OECD. 